\title{
Waterborne hyperbranched alkyd-acrylic resin obtained by miniemulsion polymerization
}

\author{
Edwin Murillo ${ }^{1 *}$ and Betty López² \\ ${ }^{1}$ Grupo de Investigación en Materiales Poliméricos - GIMAPOL, Departamento de Química, \\ Universidad Francisco de Paula Santander, San José de Cúcuta, Colombia \\ ${ }^{2}$ Grupo de Investigación en Ciencia de los Materiales, Universidad de Antioquia, Calle, \\ Medellín, Colombia \\ *edwinalbertomurillo@gmail.com
}

\begin{abstract}
Four waterborne hyperbranched alkyd-acrylic resins (HBRAA) were synthesized by miniemulsion polymerization from a hyperbranched alkyd resin (HBR), methyl methacrylate (MMA), butyl acrylate (BA) and acrylic acid (AA), by using benzoyl peroxide (BPO) and ammonium persulfate (AP) as initiators. The reaction between HBR and acrylic monomers was evidenced by differential scanning calorimetric (DSC), nuclear magnetic resonance (NMR) and gel permeation chromatography (GPC). The conversion percentage, glass transition temperature $\left(\mathrm{T}_{\mathrm{g}}\right)$, content of acrylic polymer (determined by soxhlet extraction) and molecular weight increased with the content of acrylic monomers used in the synthesis. The main structure formed during the synthesis was the HBRAA. The analysis by dynamic light scattering (DLS) showed that the particle size distribution of HBRAA2, HBRAA3 and HBRAA4 resins were mainly monomodal. The film properties (gloss, flexibility, adhesion and drying time) of the HBRAA were good.
\end{abstract}

Keywords: hyperbranched polymers, miniemulsion polymerization, alkyd-acrylic resins, properties.

\section{Introduction}

The use of renewable resources in the preparation of various industrial materials has been revitalized due to the environmental concerns. Last year, research on coating (research) was conducted aiming to the reduction of volatile organic compounds (VOCs) ${ }^{[1]}$. These latters (the VOCs) are toxic, responsible for global warming and climate changes, and photochemical ozone layer deterioration ${ }^{[1]}$. Some alternatives have been adopted to obtain ecofriendly materials were, among others, waterborne coatings and hyperbranched polymers with high solid content are being developed for this purposes ${ }^{[1-6]}$.

A hybrid polymer is composed of at least two kinds of materials, different in chemical nature, and which normally incompatible but bonded either by chemical covalent bonds or strong physical secondary intermolecular forces ${ }^{[7,8]}$. Recently, researches have been devoted to this topic ${ }^{[9-12]}$. The alkyd resins are a good alternative for obtaining environmentally friendly hybrid coatings (waterborne resins); since they can be modified by addition reactions with other materials through double bonds, offering the access to other structures and materials with novel and enhanced properties ${ }^{[13-15]}$.

The HBR exhibit short time for chemical drying, high gloss as well as chemical resistance ${ }^{[16]}$. Acrylic resins are more resistant against ultraviolet light, show shorter drying time and better chemistry resistance than alkyd resins ${ }^{[15]}$. However, the properties of gloss and hardness in a porous substrate of acrylic resins are regular ${ }^{[15]}$. Therefore, the objective of the modification of HBR with acrylic monomers is to obtain a synergetic compromise between most needed properties. The study of alkyd-acrylic resins or oil-acrylic

monomers has been only focused on materials synthesis with the lowest branching degree ${ }^{[17-22]}$.

There are two methods usually employed to synthesize alkyd-acrylic resins, which are emulsion polymerization ${ }^{[22]}$, and mini-emulsion polymerization ${ }^{[13,14]}$. The emulsion polymerization is not a suited method, because alkyd resins exhibit low hydrophilicity, since the diffusion of alkyd resins toward micelles is very slow, which produces colloidal instability (phase separation or secondary nucleation) ${ }^{[7,15]}$. The miniemulsion polymerization is the most adequate method, since it does not require the diffusion process. This is due to the polymerization occurs on the monomer droplets and the low hydrophilicity of the resin and the hydrophobicity of the co-surfactant help to avoid the Ostwald ripening process $^{[7]}$. The hydrophobic nature of the alkyd resins makes it impossible to be accommodated by traditional emulsion polymerization due to mass-transfer limitations ${ }^{[14]}$. Despite of the disadvantages of emulsion polymerization, it has been investigated in several studies ${ }^{[7,15]}$. Alkyd/acrylic resin were prepared by solution polymerization by using BPO and 2,2-azobisisobutyronitrile (AIBN) as initiators. An alkyd resin was obtained from soybean oil, glycerol, phthalic anhydride, and tetrahydrophthalic anhydride and modified with acrylic monomers. The acrylic monomers employed were MMA, BA and methacrylic acid (MAA). NMR analysis shown that acrylic groups were grafted into the polyester backbone of the alkyd via the hydrogen abstraction of the glycerol. It was also determined that the choice of initiator has no effect on graft location, but the system initiated with BPO provided spectral evidence that the BPO can directly abstract the doubly allylic hydrogen of fatty acids presents 
in the alkyd ${ }^{[23]}$. Alkyd-acrylic hybrids having final solids content of $75-80 \%$ were prepared by dropping alkyd resin (75 wt $\%$ of fatty acid based on the total alkyd) into an acrylic dispersion. The resulting suspoemulsion structures and the alkyd droplet sizes in the hybrids were dependent on the preparation procedure as well as the interfacial tension between the two liquid phases. However, when the surfactant was added to the alkyd prior to the addition of the alkyd to the latex, a multi-emulsion $(\mathrm{W} / \mathrm{O} / \mathrm{W})$ of alkyd was formed ${ }^{[20]}$. Alkyd resins were modified with acrylic monomers (BA, MMA, ethyl acrylate and ethyl methacrylate) by using a reversible-addition chain transference (soya based alkyd with a carboxy-functional trithiocarbonate). AIBN was the initiator employed. NMR spectra showed the presence of acrylic blocks the pendant fatty acids and the formation of homopolyacrylate ${ }^{[24]}$.

Hybrid waterborne alkyd-acrylic dispersions with solid content of $40 \mathrm{wt} \%$, free from any surfactant and organic solvent, were synthesized by a melt co-condensation reaction between an acrylic prepolymer bearing carboxylic groups and an alkyd resin by a phase inversion process. The acrylic prepolymer were prepared first by free radical polymerization of MMA, ethylhexyl acrylate, maleic anhydride and methacrylic acid. The alkyd resin was synthesized from soya fatty acid, phthalic anhydride, benzoic acid and pentaerythritol. The insertion of anhydride moieties within the acrylic prepolymer ensured the efficient coupling between the acrylic prepolymer and the alkyd resin and prevented the phase separation ${ }^{[25]}$.
Alkyd-acrylic resins were synthesized by emulsion polymerization and these materials presented a synergic effect $^{[22]}$. The properties of these resins were better than alkyd-acrylic blends. In the synthesis of alkyd-acrylic resins, several structures are present by the end of the reaction, which are alkyd resin, acrylic polymer and alkyd-acrylic resin ${ }^{[17,26]}$.

The synthesis of waterborne alkyd-acrylic resins has been achieved from alkyd resins with low branching degrees, but so far, there has not been any research on the synthesis of the waterborne hyperbranched alkyd-acrylic resins (HBRAA) obtained by miniemulsion polymerization from HBR. In order to continue contributing to the development of new environmentally friendly materials in this work, four HBRAA were synthesized by the polyaddition reaction between acrylic monomers and a HBR (Figure 1). The effects of acrylic monomers on the structural, thermal and film properties of HBRAA resins were studied.

\section{Experimental Section}

\subsection{Materials}

The synthesis and properties of the HBR were reported in an earlier publication, and it was named HBRA4 ${ }^{[3,27]}$. The methyl methacrylate (MMA), acrylic acid (AA) and butyl acrylate (BA). Sodium dodecyl sulfate (SDS), AP, $\mathrm{BPO}$, xylene, tetrahydrofurane (THF), sodium hydroxide, acetone, toluene, sodium chloride ( $\mathrm{NaCl})$, hexadecane (HD), toluene, chloroform and diethyl ether were purchased from

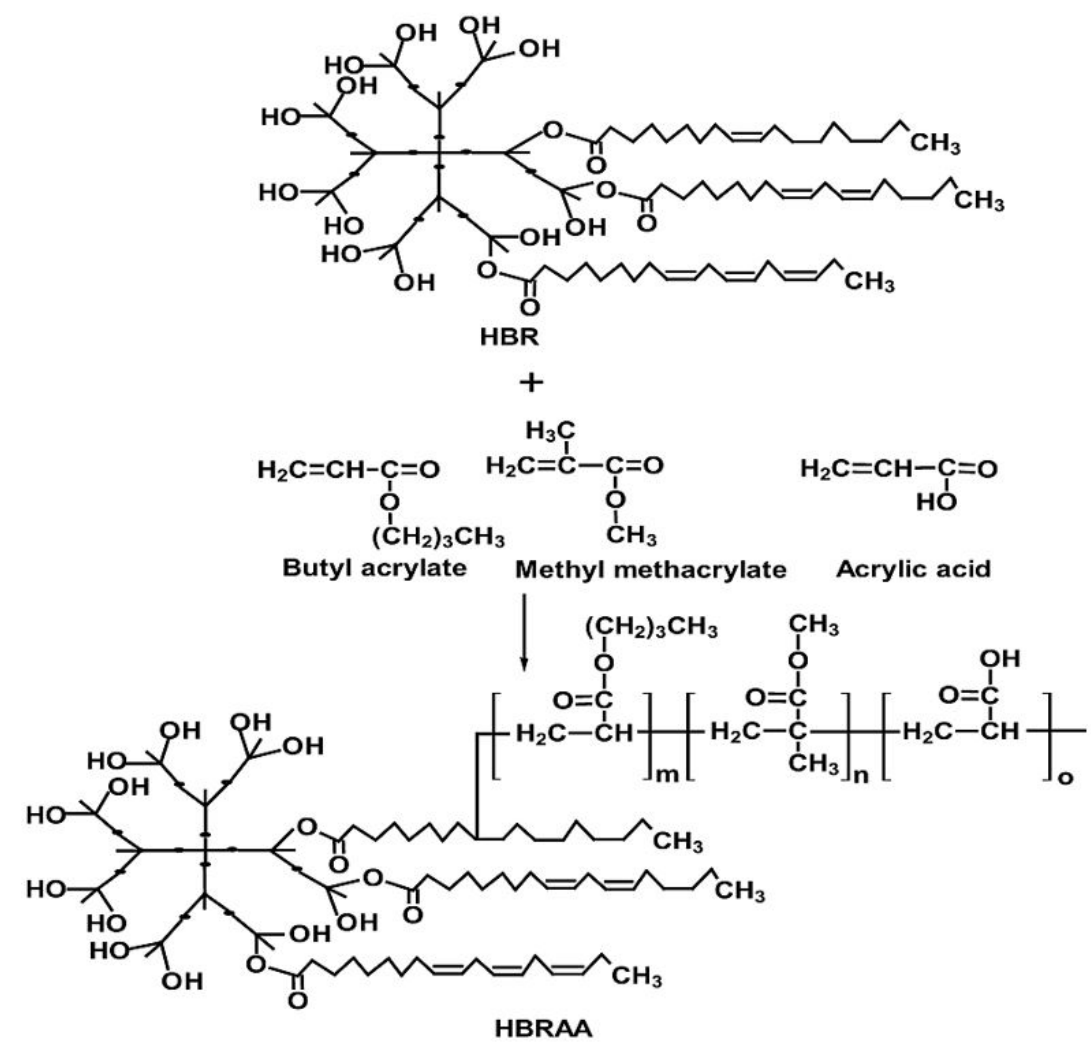

Figure 1. Schematic representation of the synthesis of a HBRAA. 
Aldrich and all used as received. The purities of all reactive chemicals are higher than $99 \mathrm{wt} \%$. Cobalt, calcium and zirconium octoates were supplied by Colorquímica S.A.

\subsection{Synthesis of the HBRAA}

In order to synthesise the HBRAA, the corresponding amount of HBR, HD ( $4 \mathrm{wt} \%$ with respect to the amounts of acrylic monomers $), \mathrm{BPO}(0.5 \mathrm{wt} \%$ with respect to amounts of acrylic monomers) and acrylic monomers were mixed to obtain a homogeneous system (hydrophobic solution). Table 1 presents the proportions of HBR and acrylic monomers employed on the synthesis. In all cases the proportions of acrylic monomers (MMA-BA-AA) were 49:50:1. A solution of SDS $(312 \mathrm{ml} 0.02 \mathrm{M})$ and AP $(40 \mathrm{ml} 0.01 \mathrm{M})$ in water were prepared in different recipients.

For preparing the miniemulsions, the hydrophobic and SDS solutions were mixed during thirty minutes using a homogenizer (UltraTurrax) at $24000 \mathrm{rpm}$ in an ice bath to avoid an increase in the temperature, which may cause premature polymerization. The obtained solution was transferred to a reactor equipped with a mechanical stirrer, condenser, and a heating system. The reaction system was kept under nitrogen atmosphere and heated to $80{ }^{\circ} \mathrm{C}$. The solution of initiator and the amount of sodium bicarbonate $(0.5 \mathrm{wt} \%$ with respect to total mix) were added to the system. Finally the system was stirred at 200 RPM during five hours. In all cases, the solid content was kept constant (40 wt \%). The reactions conversion was followed gravimetrically. The conversion study was done from extractions of small aliquots at different reaction times intervals. In all cases, two drops of an ethyl hydroquinone solution ( $1 \mathrm{wt} \%$ ) were added to stop posterior polymerization. The samples were vacuum dried at $50 \mathrm{C}$ for 48 hours. Finally, the samples were taken out and weighted.

\subsection{Characterization of the HBRAA resins}

The studies of compositional analysis were performed by a soxleht extraction technique. The HBR and HBRAA are soluble in diethyl ether, but the free acrylic polymer (without grafting in HBR) is insoluble in this solvent. The free acrylic polymer is soluble in $\mathrm{THF}^{[17,28]}$. For the quantification, the HBRAA were first submitted to soxleht extraction with diethyl ether for 24 hours and then the residue was dried and weighed. The HBR and HBRAA were extracted as previously mentioned. For the extraction of the acrylic polymer, the above residue was kept on soxleht extraction with THF for 24 hours, and the final residue was then dried and weighted. Finally other extractions were done using toluene, chloroform and acetone, in order to determine the insoluble material content. The NMR analysis was carried

Table 1. Proportions of HBR and acrylic monomers employed on the synthesis.

\begin{tabular}{ccc}
\hline HBRAA & $\begin{array}{c}\text { HBR } \\
(\boldsymbol{\%})\end{array}$ & $\begin{array}{c}\text { (MMA-BA-AA) } \\
\mathbf{( 4 9 : 5 0 : 1 )} \\
(\mathbf{\%})\end{array}$ \\
\hline HBRAA1 & 50 & 50 \\
HBRAA2 & 40 & 60 \\
HBRAA3 & 30 & 70 \\
HBRAA4 & 20 & 80 \\
\hline
\end{tabular}

out in a Bruker AC $300 \mathrm{MHz}$ spectrometer. The ${ }^{1} \mathrm{H}$ NMR spectrum was obtained by using deuterated chloroform (HBR and HBRAA4) and tetrahydrofurane as solvents (HBRAA2 and HBRAA3). The DLS analysis was done at room temperature and at $50{ }^{\circ} \mathrm{C}$ by using a Zetasizer Nano Series machine from Malvern Instruments. A $633 \mathrm{~nm}$ wavelength and an incidence angle of $173^{\circ}$ was used. GPC analysis was performed in Waters 600 equipment by using a styragel column with dimensions of $4.6 \times 300 \mathrm{~mm}$. The samples were dissolved in THF at $30{ }^{\circ} \mathrm{C}$. For the quantification, polystyrene standards were used to obtain calibration curves. Millennium 2000 software was used for data acquisition. DSC analysis was performed using TA Instrument model Q100 equipment, employing heating and cooling rates of $30{ }^{\circ} \mathrm{C} / \mathrm{min}$, under nitrogen atmosphere. Minimum film formation temperature (MFFT) analysis of the HBRAA was performed on Rhopoint equipment. The temperature was between -5 and $13^{\circ} \mathrm{C}$ and a pressure of 5 Psi. The HBRAA films, with a thickness of $75 \mu \mathrm{m}$, were applied in a plate, which had a temperature gradient $\left(-5\right.$ and $\left.13{ }^{\circ} \mathrm{C}\right)$ and a sensor that allows the calibration of intermediate temperature. For the film properties, the HBRAA were mixed with cobalt octoate $(0.6 \% \mathrm{wt})$, calcium octoate $(0.6 \% \mathrm{wt})$ and zirconium octoate $(1.8 \% \mathrm{wt})$. The gloss, adhesion, drying time and flexibility of the films were then studied. By using a film applicator, the films were applied on steel surfaces and dried at $25{ }^{\circ} \mathrm{C}$, under relative humidity of $40 \%$. The analyses of adhesion (ASTM D 3359), flexibility (ASTM D 522), specular gloss at $60^{\circ}$ and $85^{\circ}$ (ASTM D 523), and drying time (ASTM D 1640).

\section{Results and Discussion}

Figure 2 presents the results of the conversion degree of the HBRAA as a function of time. The conversion increased with the amount of polymerized acrylic monomers. This behavior has been already observed for conventional alkyd resins ${ }^{[17,28]}$. The conversion degree values of the HBRAA were the following: $95.03 \%$ for HBRAA $1,97.53 \%$ for HBRAA2, 98.99\% for HBRAA3 and 99.65\% for HBRAA4. The conversion after thirty minutes increased quickly with the content of acrylic monomers. The free radicals of BA have a preference for reacting though double bonds of the

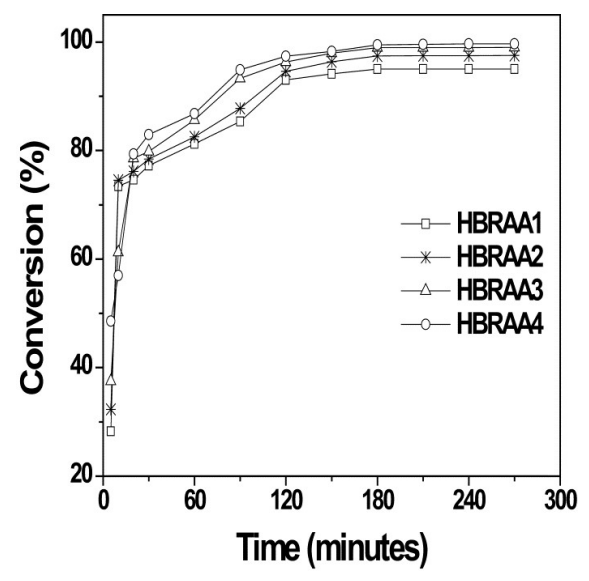

Figure 2. Conversion percentage of the HBRAA. 
$\mathrm{HBR}^{[18]}$. It has been reported in the case of MMA, which has a sterically hindered radical center ${ }^{[18]}$. Therefore the BA is more reactive than MMA, it is possible that this increasing to conversion percentage (after thirty minutes) is related with the grafting of MMA onto HBR or the beginning of termination reactions.

Another hypothetical reason of the increasing in conversion percentage at $30 \mathrm{~min}$ of reaction is that, the AA being soluble in water reacted with AP in the aqueous phase and the free radicals derived from this monomer inside the droplets, thus increasing the reaction conversion. Therefore the conversion at this time is higher with the content of this monomer. The required reaction time is around $180 \mathrm{~min}$.

For the synthesis of conventional alkyd-acrylic resins (structure with lowest branching) obtained by miniemulsion polymerization, the conversion degree was around $80 \%$. This low conversion was due to the limiting conversion ${ }^{[18]}$, which is produced by abstraction of allylic hydrogen (linolenic or linoleic acids). This produces a chain transfer to relatively inactive radical on the HBR with a reduction in the overall polymerization rate, and when approached by another active acrylic macroradical, it terminates with the formation of a grafted $\mathrm{HBR}^{[18]}$.

It can be concluded that in our study this process was minimized or was not present at all, since the conversion degree values obtained in this study were higher than those reported by Hudda et $\mathrm{a}^{[18]}$. The grafting mechanism proposed to the synthesis of the HBRAA is grafting through chain transfer and addition through the double bond ${ }^{[18]}$

An important aspect that contributed to achieve a good conversion degree was the presence of double bonds of the HBR, which are on the periphery along with the use of two initiators, which increased the probability of grafting of the acrylic monomers onto HBR.

The grating degree (GD) of the acrylic monomers in the HBR was calculated using the equation:

$$
G D=\frac{A}{B} \times 100
$$

where, $A$ and $B$ are the amount of acrylic monomers grafted onto the HBR and the amount of acrylic monomers used in the synthesis, respectively. Table 2 shows the results of compositional analysis.

The HBRAA content (hybrid resins) for all samples was high and this increased with the amount of acrylic monomers employed in the synthesis. The quantity of free acrylic polymer in the final product also increased with the content of acrylic monomers initially employed in the synthesis. These behaviors were expected because as the amount of acrylic monomers increase, the probability to form the acrylic polymer is high, which was more probable for the sample HBRAA4. To compute the grafting degree of the acrylic monomers onto HBR, this assumption was made; the amount of the free acrylic polymer (soluble in THF) is equal to non-grafted polyacrylate, since HBR and HBRAA are soluble in diethyl ether. Therefore the residues obtained after extraction operation with diethyl ether are acrylic polymer and insoluble material totally extracted in this process ${ }^{[28]}$. The grafting degree increased with the amount of HBR, it was due to the low probability of formation of the acrylic polymer and high number of double bonds available for grafting.

Because the acrylic polymer is soluble in THF, it is deduced that the final residue or insoluble fraction corresponding to the crosslinking structure contains crosslinked HBRAA. A study concerning conventional alkyd resin, using the same acrylic monomers, did not show the formation of crosslinking ${ }^{[17]}$. The HBRAA crosslinking is attributed to the high density of double bonds in the periphery and initiator content. The insoluble materials increased with the proportion of HBR employed in the synthesis. Wang et al. reported ${ }^{[28]}$ that the insoluble material is due to crosslinking of the HBR and also to the high number of acrylic chains grafted onto HBR. This corroborated the hypothesis that there are some grafted acrylic units in insoluble residue (solid that remain after the extraction process).

Figure 3 shows the NMR spectra of the HBR, HBRAA2, HBRAA3 and HBRAA4. The signals that appeared in the spectra of the samples HBRAA2 and HBRAA3 at 1.73 and $3.58 \mathrm{ppm}$, were due to protons of the THF. The signals of HBR have been explained in a previous paper $^{[3]}$. Among these signals the most important is the signal of the protons of $-\mathrm{HC}=\mathrm{CH}$ - bonds (at $5.3 \mathrm{ppm}$ ), because this signal is evidence of the reaction between acrylic monomers and the HBR. In the NMR spectra of the HBRAA, it can be observed that the signal of the protons of $-\mathrm{HC}=\mathrm{CH}$ - bonds decreased its intensity with the increase of the acrylic monomers proportion in the synthesis. This is a proof of the reaction between acrylic monomers and HBR. The HBRAA4 exhibited the lowest intensity of the signal due to protons of $-\mathrm{HC}=\mathrm{CH}$ - bonds. This is attributed to the fact that the highest amount of acrylic monomers was used and that they reacted in high yield during the synthesis of this resin. The signal around $4.0 \mathrm{ppm}$ was attributed to protons of $-\mathrm{CH}_{2}$ joined to ester groups $\left(-\mathrm{CH}_{2} \mathrm{OCOR}\right)$ and the signals of protons of the unreacted $\mathrm{OH}$ groups $\left(-\mathrm{CH}_{2} \mathrm{OH}\right)$ of linear and terminal units appeared between 3.4 y $3.6 \mathrm{ppm}$. The wide signal surrounding $2.7 \mathrm{ppm}$ was possibly due to overlapping of the $-\mathrm{CH}_{2}$ - protons of $-\mathrm{CH}_{2}-$ $\mathrm{COOH}$ and $-\mathrm{CH}_{2} \mathrm{COOCH}_{2}$ - groups. Other signals in the HBRAA spectrum between 0.5 and $2.5 \mathrm{ppm}$, were attributed to aliphatic protons (-CH, $-\mathrm{CH}_{2}$ and $\left.-\mathrm{CH}_{3}\right)$.

Table 2. Compositional analysis of the HBRAA.

\begin{tabular}{ccccc}
\hline \multirow{2}{*}{ HBRAA } & $\begin{array}{c}\text { Alkyd-acrylic resins } \\
\mathbf{( \% )}\end{array}$ & $\begin{array}{c}\text { Acrylic polymer } \\
\mathbf{( \% )}\end{array}$ & $\begin{array}{c}\text { Grafting degree } \\
\mathbf{( \% )}\end{array}$ & $\begin{array}{c}\text { Insoluble material } \\
(\%)\end{array}$ \\
\hline HBRAA1 & 59.88 & 1.01 & 97.98 & 39.11 \\
HBRAA2 & 68.99 & 1.73 & 97.12 & 29.28 \\
HBRAA3 & 80.81 & 2.08 & 97.03 & 17.11 \\
HBRAA4 & 90.01 & 2.41 & 96.97 & 7.58 \\
\hline
\end{tabular}


Figure 4 presents the size distributions of the drops and the particles. Drop sizes of the HBRAA1 were not monomodal (Figure 4a), which was possibly due to higher difficulty to break the drops of the HBR, since the HBRAA1 presented the highest content of HBR employed in the synthesis, as a result, the miniemulsification process was less effective to this sample. The HBRAA2 exhibited higher monomodal behavior than that of theHBRAA1 (Figure 4b). HBRAA3 (Figure 4c) and HBRAA4 (Figure 4d) were monomodal, but the distribution was wide, which indicates that the highest amount of acrylic monomers facilitated the rupture of the drops to form miniemulsions with small drops, which is due to low viscosity of these monomers and change on surface tension.

All HBRAA presented nanometric particle sizes (50-500 nm). Some works have reported that the final particle sizes are a one-to-one copy of the monomer droplets ${ }^{[29]}$. The HBRAA1 presented a small increase in particle size with respect to drop size (Figure 4 and Table 3), which might be attributed to: a) the amount of surfactant was not enough to stabilize the drops of this resin, b) occurrence of changes in surface tension and chain conformation, and c) coagulation between particles. The average drop sizes of the samples HBRAA2, HBRAA3 and HBRAA4 were higher than those of the average particle sizes; this was possibly caused by some change of the surface tension during the polymerization due to occurrence of homogeneous nucleation during the polymerization though of MMA and AA, since these monomers present certain solubility in water.

Additionally the shelf life of the miniemulsions (before the polymerization process) was studied. This shelf life is defined as the time required for a cream phenomenon to appear in the samples ${ }^{[30]}$. This process is a product of the Ostwald Ripening process and may occur before or after the polymerization process ${ }^{[31]}$. A hexadecane, as co-surfactant, was used to avoid the above process mentioned. It is highly hydrophobic and prevents the diffusion of the monomers from small drops toward big drops. All resins exhibited excellent stability without cream exhibition after twelve months (Table 3 ). The results of this analysis are evidence that the amount of coagulum after polymerization is possibly low, since the drop and particle size of the HBRAA are almost similar.

In order to evaluate the colloidal stability of the HBRAA, they were submitted to storage for three months at $50{ }^{\circ} \mathrm{C}$. In the Figure 5, the particle size distributions of the HBRAA
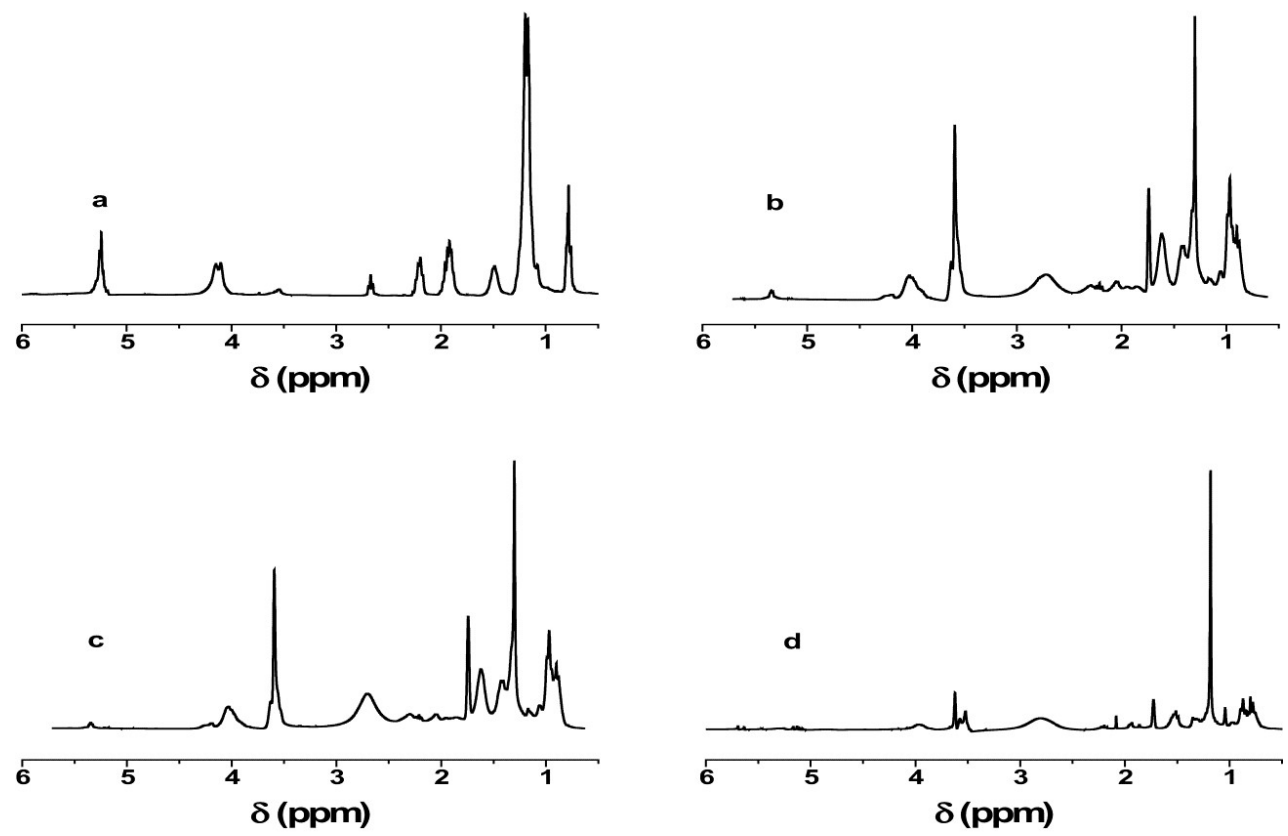

Figure 3. ' $\mathrm{H}$ RMN spectra (a) HBR; (b) HBRAA2; (c) HBRAA3 and (d) HBRAA4.

Table 3. Drop and particle average size and shelf life of the HBRAA.

\begin{tabular}{|c|c|c|c|c|c|}
\hline HBRAA & $\begin{array}{c}\text { Drop size }(\mathrm{nm}) \\
\mathrm{d}_{1}(\%) \\
\end{array}$ & $\begin{array}{c}\text { Drop size }(\mathrm{nm}) \\
\mathrm{d}_{2}(\%)\end{array}$ & $\begin{array}{c}\text { Particle size }(\mathrm{nm}) \\
\mathrm{d}_{1}(\%)\end{array}$ & $\begin{array}{c}\text { Particle size }(\mathrm{nm}) \\
\mathrm{d}_{2}(\%)\end{array}$ & Shelf life (Months) \\
\hline HBRAA1 & $\begin{array}{c}102.30 \\
(18.10 \%)\end{array}$ & $\begin{array}{c}509.40 \\
(81.90 \%)\end{array}$ & $\begin{array}{c}164.00 \\
(60.20 \%)\end{array}$ & $\begin{array}{c}662.00 \\
(39.80 \%)\end{array}$ & $>12$ \\
\hline HBRAA2 & $\begin{array}{c}50.27 \\
(10.50 \%)\end{array}$ & $\begin{array}{c}361.80 \\
(89.50 \%)\end{array}$ & $\begin{array}{c}55.41 \\
(4.80 \%)\end{array}$ & $\begin{array}{c}319.40 \\
(95.20 \%)\end{array}$ & $>12$ \\
\hline HBRAA3 & $\begin{array}{l}271.90 \\
(100 \%)\end{array}$ & - & 200.20 & - & $>12$ \\
\hline HBRAA4 & $\begin{array}{l}206.80 \\
(100 \%)\end{array}$ & - & 160.60 & - & $>12$ \\
\hline
\end{tabular}



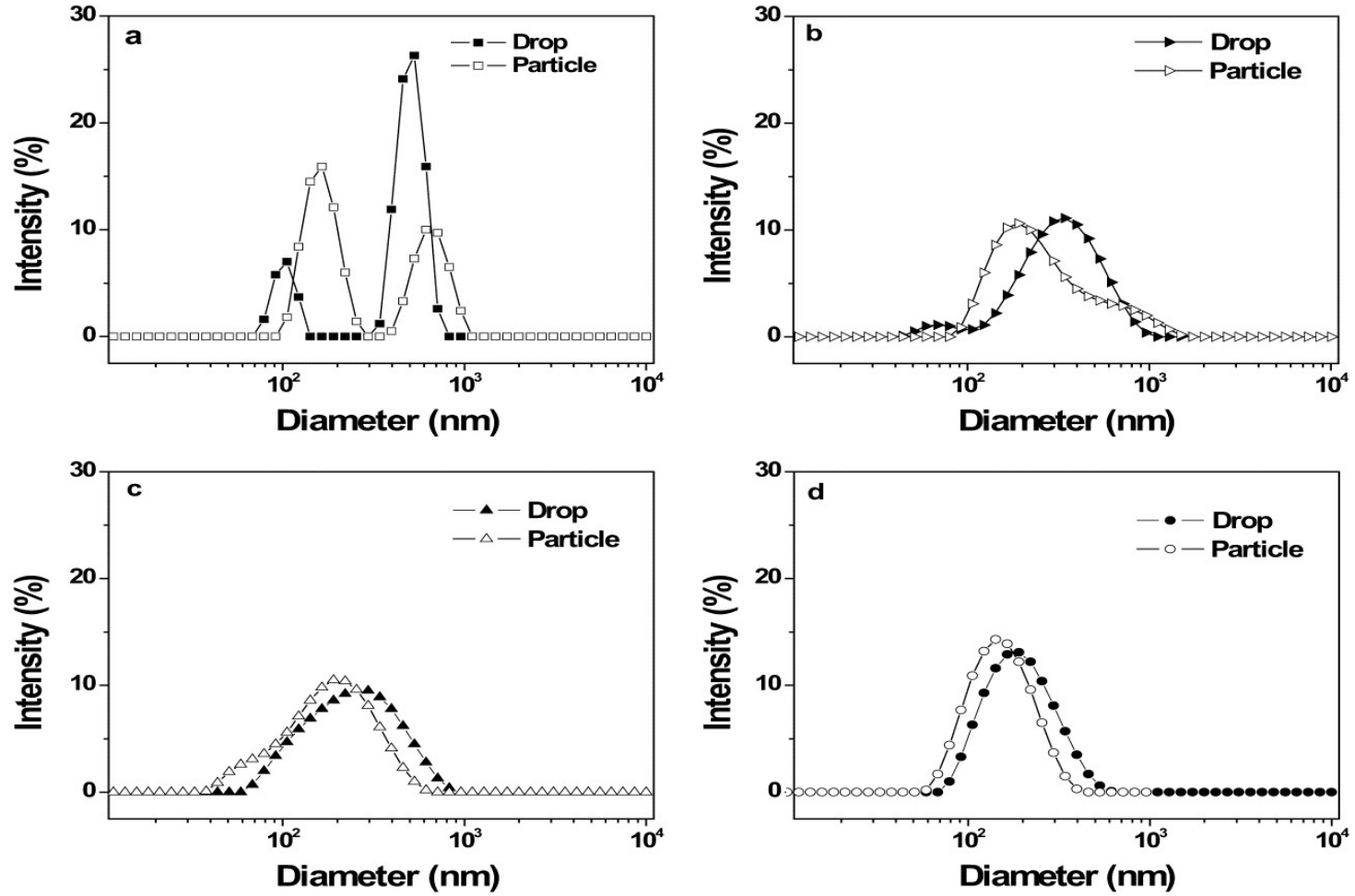

Figure 4. Drop and particle size distributions of the HBRAA (a) HBRAA1; (b) HBRAA2; (c) HBRAA3 and (d) HBRAA4.
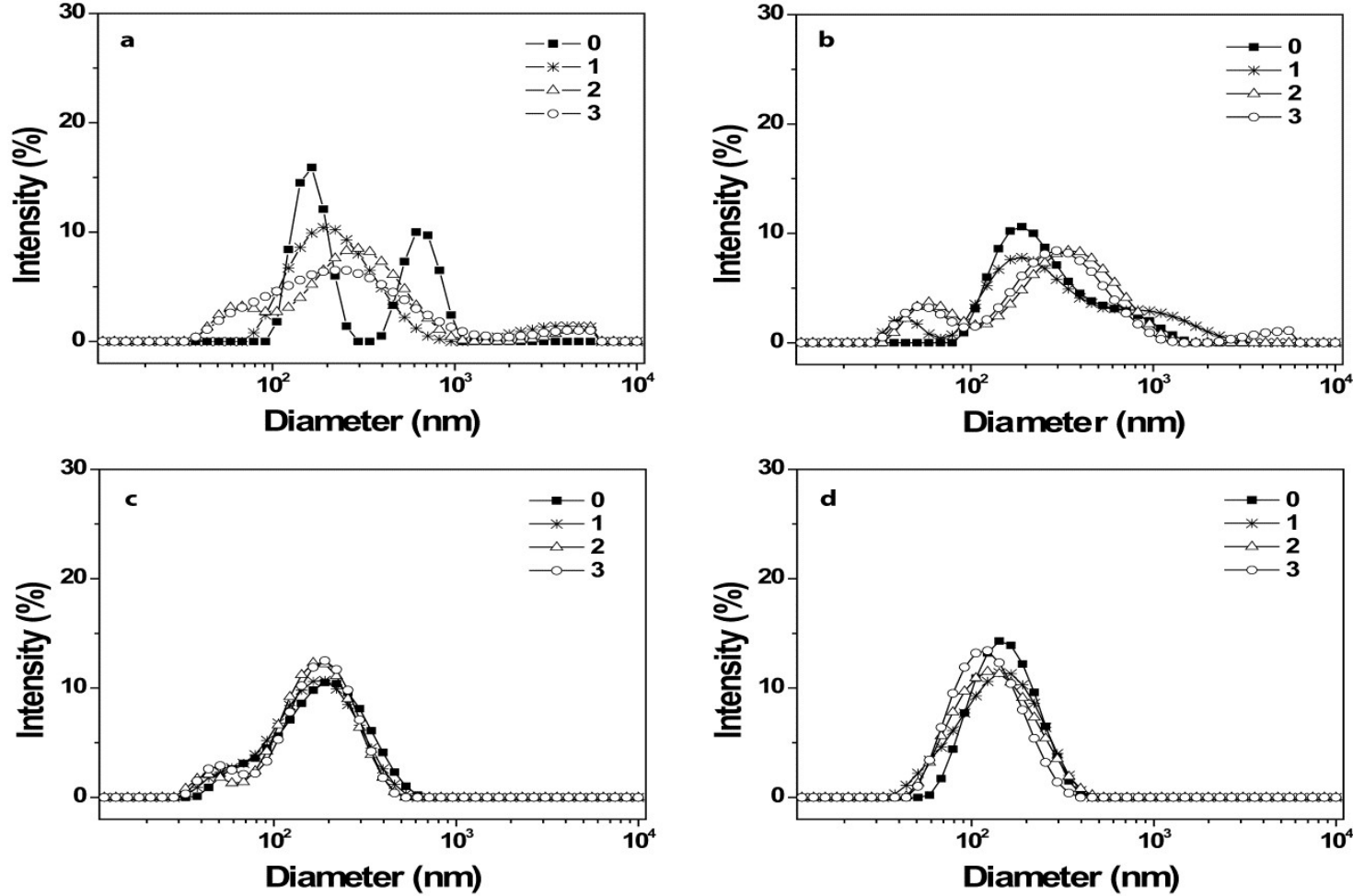

Figure 5. Particle size distributions of the HBRAA at room temperature ( 0 months) and at $50^{\circ} \mathrm{C}$ (one, two and three months). (a) HBRAA1; (b) HBRAA2; (c) HBRAA3 and (d) HBRAA4. 
are observed. During the storage process the flocculation, deflocculation, coagulation and migration of surfactant from the aqueous phase toward the particles can occur. All these processes affect the colloidal stability. The coagulation process produces an increase in particle size. This phenomenon was observed mainly in the HBRAA1. These resins at room temperature $(0$ month) presented two distributions, and then at storage at $50{ }^{\circ} \mathrm{C}$, it showed a wide distribution and the presence of an additional peak at $3551 \mathrm{~nm}$.

The HBRAA2, after one month of storage at $50{ }^{\circ} \mathrm{C}$, exhibited an additional peak at around $45.48 \mathrm{~nm}$, and a particle size distribution more wide than at room temperature (0 month). The peak at $45.46 \mathrm{~nm}$ is possibly due to the deflocculation process. Furthermore, in the third month it presented another peak at around $4000 \mathrm{~nm}$, which is probably due to the coagulation or flocculation process.

The HBRAA3 after one month presented another small distribution with a particle size of $45.48 \mathrm{~nm}$. However, the particle size distribution is very similar at different times (0, one, two and three months). The HBRAA4 was the unique sample that showed a monomodal distribution and a particle size distribution very stable with the time. Therefore, it exhibited the highest colloidal stability.

The Brownian movement of the particles increased with temperature. This improves the coalescence of the particles, according to the results obtained in this study. It can be concluded that HBRAA3 and HBRAA4 exhibited higher colloidal stability than HBRA1 and HBRAA2 resins. The behavior showed by the HBRAA3 and HBRA4 are possibly related to the small particle size, and high covering of the particle surface by the surfactant.

Table 4 presents the results of the gel permeation chromatography (GPC) analysis. The values of number average molar masses $(\mathrm{Mn})$ increased with the proportion of acrylic monomers employed in the synthesis and these are higher than HBR $(6611 \mathrm{~g} / \mathrm{mol})^{[27]}$. The great difference between the Mn values of the HBRAA and HBR was due to the synthesis process, since a polymer with high molar mass can be obtained by miniemulsion polymerization ${ }^{[19]}$. The polydispersity index (PI) of the HBRAA2 was similar to HBRAA1 and HBRAA3 and lower than HBRAA4.

According to these results, PI was independent of the amount of acrylic monomers employed in the synthesis. The difference on PI was possibly due to the miniemulsion polymerization process, which is random, since the acrylic monomers have so many places where they can be grafted.

Figure 6 shows the DSC thermograms of the all HBRAA, which presented higher glass transition temperature $\left(\mathrm{T}_{\mathrm{g}}\right)$ than HBR $\left(-49.8^{\circ} \mathrm{C}\right)^{[27]}$. The $\mathrm{T}_{\mathrm{s}}$ values of the HBRAA were as follow: HBRAA1, $-24.7^{\circ}{ }^{\circ} \mathrm{C}$, HBRAA2, $-16.6^{\circ} \mathrm{C}$, HBRAA3, $-14.5^{\circ} \mathrm{C}$ and HBRAA $4,-12.9^{\circ} \mathrm{C}$. All HBRAA

Table 4. Mn, Mw and PI of the HBRAA.

\begin{tabular}{cccc}
\hline HBRAA & $\begin{array}{c}\text { Mn } \\
(\mathbf{g} / \mathbf{m o l})\end{array}$ & $\begin{array}{c}\text { Mw } \\
(\mathbf{g} / \mathbf{m o l})\end{array}$ & PI \\
\hline HBRAA1 & 45716 & 99812 & 2.75 \\
HBRAA2 & 50061 & 108844 & 2.17 \\
HBRAA3 & 65202 & 182123 & 2.79 \\
HBRAA4 & 90826 & 413679 & 4.55 \\
\hline
\end{tabular}

have an increased $\mathrm{T}_{\mathrm{g}}$ values with respect to the amount of acrylic monomers employed in the synthesis. Despite that the polybutyl acrylate has a $\mathrm{T}_{\mathrm{g}}$ value around $-51.1{ }^{\circ} \mathrm{C}^{[32]}$, polymethyl methacrylate confers high structural stiffness to the HBRAA, since, it has a $\mathrm{T}$ value around $105^{\circ} \mathrm{C}^{[33]}$. A second $\mathrm{T}_{\mathrm{g}}$ was observed for HBRAA2 at $-0.5^{\circ} \mathrm{C}, \mathrm{HBRAA} 3$ at $-0.90^{\circ} \mathrm{C}$ and HBRAA 4 at $-2.1{ }^{\circ} \mathrm{C}$, which are possibly due to free acrylic polymer ${ }^{[17]}$.

MMFT is the minimum temperature that is required for the latex to form a clear optically and uniform film, once it is applied on a surface. At lower temperature than MMFT, the film is opaque or granular ${ }^{[34]}$. The MMFT values of the HBRAA were as follow: HBRAA $1<-5{ }^{\circ} \mathrm{C}$, HBRAA2 $-5^{\circ} \mathrm{C}$, HBRAA3 $-3.8^{\circ} \mathrm{C}$ and HBRAA4 $3.0^{\circ} \mathrm{C}$. According to these results, all resins presented a good film formation, even at lower temperatures, which is very adequate for their use for room temperature coating. These results are very important since none of HBRAA require the use of a coalescent agent for drying, which is an advantage from environmental (reduction of volatile organic substances), economic (reduction in the cost of the formulation) and synthetic (another variable to control) aspects point of views. The MMFT values of the HBRAA presented the same behavior on $\mathrm{T}_{\mathrm{g}}$ for all these resins and the which was lower than MFFT.

For an application of a binder, it is very important that their(s) film properties should be determined, since a good film formation is required to ensure suitable properties for the coating. In a previous study ${ }^{[3]}$, the film properties of HBR were evaluated, and these will be compared here with those of the HBRAA. Table 5 presents the results of the gloss, adherence, drying time and flexibility analyses. All films exhibited transparency. All HBRAA presented lower gloss than $\operatorname{HBR}\left(60^{\circ} / 85^{\circ}=89.9 / 983\right)^{[3]}$. The gloss values of the HBRAA decreased with the increase of the acrylic monomers content. This behavior was expected, since the gloss value of acrylic resins is lower than alkyd resins ${ }^{[2,16]}$.

When the gloss value of a resin, measured at $60^{\circ}$, is higher than $70^{\circ}$, the resin presents a high gloss ${ }^{[1]}$. Therefore, these resins exhibited a high gloss. The adhesion of the HBRAA was superior to the HBR $(90 \%)^{[3]}$. The behavior

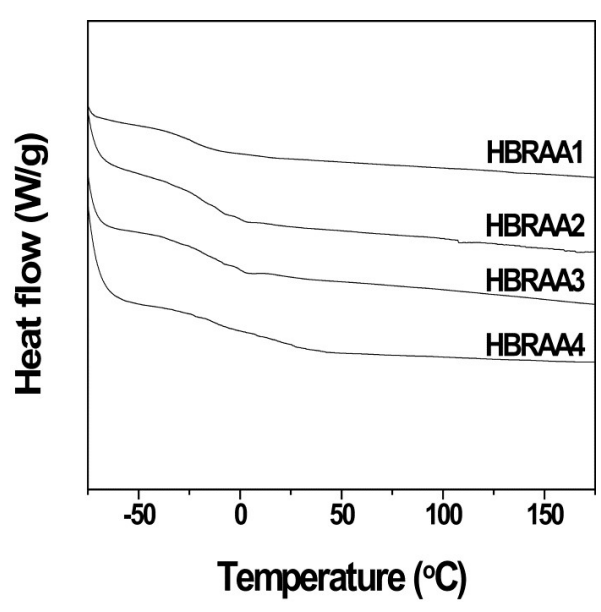

Figure 6. DSC thermograms of the HBRAA. 
Table 5. Values of gloss, adhesion, drying time and flexibility of the HBRAA.

\begin{tabular}{|c|c|c|c|c|}
\hline HBRAA & $\begin{array}{c}\text { Gloss } \\
60^{\circ} / 85^{0} \\
\end{array}$ & $\begin{array}{c}\text { Adhesion } \\
(\%)\end{array}$ & Flexibility & $\begin{array}{c}\text { Drying time } \\
\text { (min) }\end{array}$ \\
\hline HBRAA1 & $85,5 / 92,5$ & 100 & Pass & 90 \\
\hline HBRAA2 & $83,7 / 89,0$ & 100 & Pass & 80 \\
\hline HBRAA3 & $79,5 / 88,9$ & 100 & Pass & 72 \\
\hline HBRAA4 & $71,9 / 87,8$ & 100 & Pass & 45 \\
\hline
\end{tabular}

was expected because the acrylic resins present a good adherence $^{[35]}$. The flexibility of the HBRAA was good since none of the resins presented severe fracture or rupture after analysis. The drying time of the HBRAA was inferior to that of HBR (204 min. $)^{[3]}$, and decreased with the content of acrylic monomers. During the drying process, the solvent evaporation (physical drying) occurs at first and then the oxidative process (crosslinking through double bonds). When the HBR is modified with acrylic monomers, the drying process is mainly physical. Moreover, the oxidative drying is slower than physical drying, due to the low reactivity of the double bond $(-\mathrm{HC}=\mathrm{CH}-)$.

\section{Conclusions}

Different environmentally friendly HBRAA were obtained in this study, which contribute to the development of new materials. In all cases, the conversion percentage of the reaction was high. The particle size of the HBRAA was mainly nanometric. This is very good, since it confers a high superficial area, which is very important in the coating industry. All HBRAA presented better adhesion, flexibility and drying time than HBR, but HBR exhibited the higher gloss than HBRAA. This led us to conclude that all HBRAA exhibited a synergy in their properties. The HBRAA3 and HBRAA4 exhibited higher colloidal stability than the HBRAA1 and HBRAA2. An important result is that none of the HBRAA need coalescent agent to the drying process, since the HBRAA presented lower MFFT values than room temperature.

\section{References}

1. Bat, E., Gunduz, G., Kisakurek, D., \& Akhmedov, I. M. (2006). Synthesis and characterization of hyperbranched and air drying fatty acid based resins. Progress in Organic Coatings, 55(4), 330-336. http://dx.doi.org/10.1016/j.porgcoat.2006.01.005.

2. Nabuurs, T., Baijards, R. A., \& German, A. L. (1996). Alkydacrylic hybrid systems for use as binders in waterborne paints. Progress in Organic Coatings, 27(1-4), 163-172. http://dx.doi. org/10.1016/0300-9440(95)00533-1.

3. Murillo, E. A., Vallejo, P. P., \& López, B. L. (2010). Synthesis and characterization of hyperbranched alkyd resins based on tall oil fatty acids. Progress in Organic Coatings, 69(3), 235240. http://dx.doi.org/10.1016/j.porgcoat.2010.04.018.

4. Saravari, O., Phapant, P., \& Pimpan, V. (2005). Synthesis of water-reducible acrylic-alkyd resins based on modified palm oil. Journal of Applied Polymer Science, 96(4), 1170-1175. http://dx.doi.org/10.1002/app.21009.

5. Murillo, E. A., López, B. L., \& Brostow, W. (2012). Thermal, hydrolytic, anticorrosive, and tribological properties of alkydsilicone hyperbranched resins with high solid content. Journal of Applied Polymer Science, 124(5), 3591-3599. http://dx.doi. org/10.1002/app.34611.
6. Murillo, E. A., \& López, B. L. (2011). Novel waterborne hyperbranched acrylated-maleinized alkyd resins. Progress in Organic Coatings, 72(4), 731-738. http://dx.doi.org/10.1016/j. porgcoat.2011.08.004.

7. Guyot, A., Landfester, K., Schork, F. J., \& Wang, Ch. (2007). Hybrid polymer latexes. Progress in Polymer Science, 32(12), 1439-1461. http://dx.doi.org/10.1016/j.progpolymsci.2007.07.003.

8. Murillo, E. A., López, B. L., \& Brostow, W. (2011). Synthesis and characterization of novel alkyd-silicone hyperbranched nanoresins with high solid contents. Progress in Organic Coatings, 72(3), 292-298. http://dx.doi.org/10.1016/j. porgcoat.2011.04.019.

9. Murillo, E. A., López, B. L., \& Hess, M. (2004). Synthesis and characterization of a pressure-sensitive adhesive based on an isobutyl acrylate / 2-ethylhexyl acrylate copolymer. e-polymer, 28, 1-10. http://dx.doi.org/10.1515/epoly.2004.4.1.288.

10. Wang, C., Chu, F., Graillat, C., Guyot, A., Gauthier, C., \& Chapel, J. P. (2005). Hybrid polymer latexes: acrylicspolyurethane from miniemulsion polymerization: properties of hybrid latexes versus blends. Polymer, 46(4), 1113-1124. http://dx.doi.org/10.1016/j.polymer.2004.11.051.

11. Murillo, E. A., \& López, B. L. (2006). Study of the impact resistance of physically and dynamically vulcanized mixtures of PP/EPDM. Macromolecular Symposia, 242(1), 131-139. http://dx.doi.org/10.1002/masy.200651020.

12. Silber, S., Reuter, E., Stüttgen, A., \& Albrecht, G. (2002). New concepts for the synthesis of wetting and dispersing additives for water-based systems. Progress in Organic Coatings, 45(2-3), 259-266. http://dx.doi.org/10.1016/S0300-9440(02)00064-4.

13. Tsavalas, J., Luo, Y., Hudda, L., \& Schork, F. (2003). Limiting conversion phenomenon in hybrid miniemulsion polymerization. Polymer Reaction Engineering, 11(3), 277-304. http://dx.doi. org/10.1081/PRE-120023904.

14. Tsavalas, J., Gooch, J., \& Schork, F. J. (2000). Water-based crosslinkable coatings via miniemulsion polymerization of acrylic monomers in the presence of unsaturated polyester resin. Journal of Applied Polymer Science, 75(7), 916-927. http:// dx.doi.org/10.1002/(SICI)1097-4628(20000214)75:7<916::AIDAPP8>3.0.CO;2-Z.

15. Van Hamersveld, E. M. S., Van Es, G. S., German, A., Cuperus, F., Weissenborn, P., \& Hellgren, A. (1999). Oil-acrylic hybrid latexes as binders for waterborne coatings. Progress in Organic Coatings, 35(1-4), 235-246. http://dx.doi.org/10.1016/S03009440(99)00040-5.

16. Lindeboom, J. (1998). Air-drying high solids alkyd pants for decorative coatings. Progress in Organic Coatings, 34(1-4), 147-151. http://dx.doi.org/10.1016/S0300-9440(98)00034-4.

17. Wu, X., Schork, F., \& Gooch, J. (1999). Hybrid miniemulsion polymerization of acrylic/alkyd systems and characterization of the resulting polymers. Journal of Polymer Science. Part A, Polymer Chemistry, 37(22), 4159-4168. http://dx.doi. org/10.1002/(SICI)1099-0518(19991115)37:22<4159::AIDPOLA15>3.0.CO;2-N.

18. Hudda, L., Tsavalas, J. G., \& Schork, F. J. (2005). Simulation studies on the origin of the limiting conversion phenomenon 
in hybrid miniemulsion polymerization. Polymer, 46(4), 9931001. http://dx.doi.org/10.1016/j.polymer.2004.11.035.

19. Wang, Q., Fu, S., \& Yu, T. (1994). Emulsion polymerization. Progress in Polymer Science, 19(4), 703-753. http://dx.doi. org/10.1016/0079-6700(94)90031-0.

20. Jowkar-Deriss, M., \& Karlsson, O. J. (2004). Morphologies and droplet sizes of alkyd-acrylic hybrids with high solids content. Colloids and Surfaces. A, Physicochemical and Engineering Aspects, 245(1-3), 115-125. http://dx.doi.org/10.1016/j. colsurfa.2004.07.003.

21. Quintero, C., Mendon, S. K., Smith, O. W., \& Thames, S. F. (2006). Miniemulsion polymerization of vegetable oil macromonomers. Progress in Organic Coatings, 57(3), 195201. http://dx.doi.org/10.1016/j.porgcoat.2006.08.011.

22. Heiskanen, N., Jämsä, S., Paajanen, L., \& Koskimies, S. (2010). Synthesis and performance of alkyd-acrylic hybrid binders. Progress in Organic Coatings, 67(3), 329-338. http://dx.doi. org/10.1016/j.porgcoat.2009.10.025.

23. Dziczkowski, J., Dudipala, V., \& Soucek, M. D. (2012). Grafting sites of acrylic mixed monomers onto unsaturated fatty acids: Part 2. Progress in Organic Coatings, 73(4), 308-320. http:// dx.doi.org/10.1016/j.porgcoat.2010.12.006.

24. Dziczkowski, J., Chatterjee, U., \& Soucek, M. D. (2012). Route to co-acrylic modified alkyd resins via a controlled polymerization technique. Progress in Organic Coatings, 73(4), 355-365. http://dx.doi.org/10.1016/j.porgcoat.2011.03.003.

25. Elrebii, M., Mabrouk, A. B., \& Boufi, S. (2014). Synthesis and properties of hybrid alkyd-acrylic dispersions and their use in VOC-free waterborne coatings. Progress in Organic Coatings, 77(4), 757-764. http://dx.doi.org/10.1016/j.porgcoat.2013.12.016.

26. Tsavalas, J. G., Luo, Y., \& Schork, F. J. (2003). Grafting mechanisms in hybrid miniemulsion polymerization. Journal of Applied Polymer Science, 87(11), 1825-1836. http://dx.doi. org/10.1002/app.11916.

27. Murillo, E. A., Vallejo, P. P., \& López, B. L. (2011). Effect of tall oil fatty acids content on the properties of novel hyperbranched alkyd resins. Journal of Applied Polymer Science, 120(6), 3151-3158. http://dx.doi.org/10.1002/app.33502.

28. Wang, S. T., Schork, F. J., Poehlein, G. W., \& Gooch, J. W. (1996). Emulsion and miniemulsion copolymerization of acrylic monomers in the presence of alkyd resin. Journal of Applied Polymer Science, 60(12), 2069-2076. http://dx.doi. org/10.1002/(SICI)1097-4628(19960620)60:12<2069::AIDAPP4>3.0.CO;2-K.

29. Schork, F. J., Luo, Y., Smulders, W., Russum, J. P., Butte, A., \& Fontenot, K. (2005). Miniemulsion Polymerization. Advances in Polymer Science, 175, 129-255. http://dx.doi.org/10.1007/ b100115.

30. Schork, F. J., Poehlein, G. W., Wang, S., Reimers, J., Rodrigues, J., \& Samer, C. (1999). Miniemulsion polymerization. Colloids and Surfaces. A, Physicochemical and Engineering Aspects, 153(1-3), 39-45. http://dx.doi.org/10.1016/S09277757(98)00424-5.

31. Landfester, K., Schork, F. J., \& Kusuma, V. A. (2003). Particle size distribution in mini-emulsion polymerization. Comptes Rendus. Chimie, 6(11-12), 1337-1342. http://dx.doi.org/10.1016/j. crci.2003.07.019.

32. Merkel, M. P., Dimonie, V. L., El-Aasser, M. S., \& Vanderhoff, J. W. (1987). Process parameters and their effect on grafting reactions in core/shell latexes. Journal of Polymer Science. Part A, Polymer Chemistry, 25(7), 1755-1767. http://dx.doi. org/10.1002/pola.1987.080250705.

33. Matsumoto, A., Kodama, K., Aota, H., \& Capek, I. (1999). Kinetics of emulsion crosslinking polymerization and copolymerization of allyl methacrylate. European Polymer Journal, 35(8), 1509-1517. http://dx.doi.org/10.1016/S00143057(98)00216-X.

34. Esser, R. J., Devona, J. E., Setzke, D. E., \& Wagemans, L. (1999). Water based crosslinkable surface coatings. Progress in Organic Coatings, 36(1-2), 45-52. http://dx.doi.org/10.1016/ S0300-9440(99)00019-3.

35. Kin, H., Hayashi, S., \& Mizumachi, H. (1998). Miscibility and fracture energy of probe tack for acrylic pressure-sensitive adhesives: acrylic copolymer/tackifier resin systems. Journal of Applied Polymer Science, 69(3), 581-587. http://dx.doi. org/10.1002/(SICI)1097-4628(19980718)69:3<581::AIDAPP18>3.0.CO;2-W.

Received: Sept. 18, 2015

Revised: Apr. 15, 2016

Accepted: Apr. 28, 2016 